\title{
Pandemia de COVID-19: preparando la lucha contra la peste del siglo XXI
}

\section{COVID-19 pandemic: preparing for the XXI century plague}

\author{
Patricio Santillán-Doherty*
}

*Instituto Nacional de Enfermedades Respiratorias Ismael Cosío Villegas. Ciudad de México, México.

\begin{abstract}
RESUMEN. A fines del año 2019, en China, apareció un cuadro de infección respiratoria aguda consecuencia de un coronavirus nuevo, de cuadros graves, gran contagiosidad y mortalidad. Rápidamente, éste se diseminó más allá del país original, alcanzando proporciones de pandemia. Esto ha obligado a los sistemas de atención sanitaria de los países afectados a adoptar medidas para ajustar sus recursos en la preparación y respuesta de la llegada de esta pandemia; México, lo declaró emergencia sanitaria nacional el 30 de marzo de 2020. Estos preparativos y reacciones incluyen la optimización de los recursos disponibles, el allegamiento de nuevos recursos y la adaptación de áreas hospitalarias para el manejo de pacientes en situación grave. La respuesta a esta nueva enfermedad va desde entender sus mecanismos de daño, proponer tratamientos, controlar los recursos hospitalarios y, sobre todo, contener y mitigar a la población para reducir la razón de contagiosidad lo más posible.
\end{abstract}

Palabras clave: COVID-19, SARS-CoV-2, insuficiencia respiratoria, reconversión hospitalaria.

... testimonio de lo que fue necesario hacer y que sin duda deberían seguir haciendo contra el terror y su arma infatigable, a pesar de sus desgarramientos personales, todos los hombres que, no pudiendo ser santos, se niegan a admitir las plagas y se esfuerzan, no obstante, en ser médicos.

La peste. Albert Camus, 1947

Independientemente de las interpretaciones literarias que puedan surgir a partir de su novela, el Premio Nobel de Literatura, Albert Camus, describió en La peste las acciones, las actitudes, los ánimos y los apuros, como si hubiera estado ahí, de aquéllos que: «... no pudiendo ser santos, se niegan a admitir las plagas y se esfuerzan, no obstante,

Correspondencia:

Dr. Patricio Santillán-Doherty

Dirección Médica. Instituto Nacional de Enfermedades Respiratorias

Ismael Cosío Villegas.

Correo electrónico: patricio.santilland@gmail.com

Trabajo recibido: 30-III-2020; aceptado: 30-III-2020.
ABSTRACT. Towards the end of 2019 in China, a new coronavirus produced acute respiratory infection appeared. It soon became a worldwide pandemic which has pushed all medical care systems to adopt protocols to manage the situation, adjust resources required and to adapt medical areas for patient care; Mexico declare national sanitary emergency on march 30, 2020. The response to this new infection requires to understand its disease mechanisms, design and evaluate treatments, control of medical resources and, above all, the contention and mitigation within the general population in order to reduce contagiousness as much as possible.

Keywords: COVID-19, SARS-CoV-2, respiratory failure, hospital reconversion.

en ser médicos [y médicas]». En esta novela, Camus escribe las peripecias del Dr. Rieux y las de aquellos médicos que tuvieron que atender una epidemia provocada por la aparición de Yersinia pestis en Orán, una ciudad de Argelia. Pese a que esta obra fue escrita a mediados del siglo XX, desde hace muchos siglos, las epidemias atañen al trabajo de médicas y médicos y, ya en pleno siglo XXI, a una gran cantidad de profesionales, técnicos y personal de apoyo que son los que conforman el gran equipo de atención de la salud moderno, y son las y los que ahora «... se esfuerzan, no obstante, en ser médicos».

En México, el INER cada año, durante la temporada que va de octubre a marzo, se enfrenta al manejo de cantidades variables de pacientes con infecciones respiratorias agudas no graves y graves (infección respiratoria aguda/infección respiratoria aguda grave). Éste fenómeno conocido explica la importancia de las infecciones respiratorias agudas como causa relevante de mortalidad en nuestro país (influenza y neumonías). Por tanto, no es infrecuente que nuestro instituto sufra una presión importante al verse sobrepasado en su capacidad para 
atender pacientes graves que requieren manejo ventilatorio.

\section{COVID-19}

En diciembre de 2019, apareció en China un grupo de pacientes con infección por un coronavirus no conocido previamente. ' Este hecho disparó, desde enero de 2020, una respuesta coordinada con las autoridades de la Secretaría de Salud para preparar la llegada a nuestro país de este virus.

Era la mañana del 2 de enero de 2020, cuando, en lo personal, recuerdo el mensaje que recibí del Dr. Gustavo Reyes Terán, titular de la Comisión Coordinadora de Institutos Nacionales de Salud y Hospitales de Alta Especialidad de la Secretaría de Salud, que decía: «Brote de neumonía en China. Debemos estar pendientes. Sirve revisar los protocolos de atención». A partir del 27 de febrero, fecha en la que el INER internó al primer paciente diagnosticado con infección por SARS-CoV-2 (conocida mejor la enfermedad como COVID-19) es que estas actividades se fueron intensificado.

En términos generales, se espera que la gran mayoría de los pacientes infectados por SARS-CoV-2 (alrededor del 80\%) será casos leves o muy leves (incluso asintomáticos); aproximadamente, el $15 \%$ tendrá enfermedad moderada y, más o menos, un $5 \%$ será casos graves. Estos últimos, los moderados y graves, requerirán atención hospitalaria e incluso manejo de cuidados intensivos (por ejemplo, apoyo con ventilación mecánica). Por un lado, los casos leves, muy leves y asintomáticos requerirán manejo ambulatorio en casa; éstos serán los que mayoritariamente transmitirán la enfermedad y, al ser manejados ambulatoriamente, requieren ser contenidos en sus hogares para evitar la diseminación del virus. Muchos de ellos serán los contactos de pacientes que desarrollarán enfermedad grave y estarán internados en los hospitales, por lo que existen razones epidemiológicas para solicitarles que se mantengan recluidos en cuarentena domiciliaria (por lo menos por 14 días). Por otro lado, la alta razón de contagio exige la participación activa de la sociedad para reducir las interacciones físicas entre las personas con el fin de mitigar dicho riesgo de contagio. Todo esto ha sido reconocido el 30 de marzo de 2020 mediante la Declaración de Emergencia Sanitaria. $^{2}$

Entonces, la contención (la reclusión de enfermos contagiados) y la mitigación (la disminución de interacciones sociales para reducir el riesgo de contagio) resultan ser acciones sociales muy importantes. Estas acciones encuentran su sustento ético en valores como la empatía y la solidaridad: dejar de pensar en función de uno mismo para introducir, en cambio, un pensamiento comunitario que se convierta en una acción ética mediante la cual la sociedad tiene la oportunidad de participar en el control de la pandemia para reducir la aparición de casos nuevos de manera masiva, bajar la presencia de casos graves y mantener funcional el sistema de atención de la salud al evitar la llegada de pacientes de manera abrumadora, sobrepasando la capacidad instalada para la atención de estos pacientes.

\section{RECONVERSIÓN HOSPITALARIA}

De manera frecuente, la afluencia de estos pacientes obliga a adaptar áreas de atención médica convencional en áreas de atención con equipamiento especializado para la atención de infección respiratoria aguda grave, lo que implica el acomodo de equipamiento para la monitorización, la ventilación mecánica, la infusión de medicamentos y otros aditamentos de manera similar a la que presenta cualquier unidad de terapia intensiva convencional. Al mismo tiempo, se debe dotar a dichas áreas reequipadas con el personal adecuado y suficiente para contar con el nivel de atención óptimo similar al de unidades de terapia intensiva (por ejemplo, la relación paciente/enfermera, lo ideal para esta situación es que fuera de 1:1, cosa que difícilmente se puede lograr sin apoyos externos). A todo este proceso, se le conoce como «reconversión hospitalaria» y es algo conocido y practicado comúnmente al enfrentar contingencias debidas a desastres naturales, conflictos bélicos o epidemias. La afluencia de pacientes graves se incrementa y las unidades hospitalarias deben responder más allá de su capacidad instalada normal. Este fenómeno, en el INER, es perfectamente conocido, y anualmente adaptamos un porcentaje variable de camas para tratar pacientes con infección respiratoria aguda grave e insuficiencia respiratoria.

Así, según el plan de reconversión estructurado, el INER fue designado como «Hospital COVID». Al igual que el Instituto Nacional de Ciencias Médicas y Nutrición Salvador Zubirán, constituyeron las dos instituciones dedicadas exclusivamente a la atención de COVID-19; si bien otras instituciones hermanas se integraron de manera parcial según sus capacidades. Por este motivo, se ha tenido que reprogramar toda las actividades de atención rutinaria (atención no-COVID), como consulta externa, internamientos programados, estudios invasivos, cirugías programadas y redirigir las necesidades de esos pacientes con problemas respiratorios diferentes de COVID-19 hacia otras instituciones. ${ }^{3}$

\section{PROTECCIÓN DEL PERSONAL DE ATENCIÓN DE LA SALUD}

El INER se encuentra convertido en una gran Unidad de Terapia Intensiva, donde, gracias al trabajo coordinado de un equipo multidisciplinario de profesionales, técnicos y personal paramédico, los pacientes reciben atención médica 
Neumol Cir Torax. 2020; 79 (1): 4-7

especializada; en él, participan no sólo médicas y médicos capacitados, sino una gran cantidad de enfermeras, químiCOS, técnicos inhaloterapéutas, trabajadoras y trabajadores sociales, psicólogas, nutricionistas, camilleros, personal de intendencia, personal de vigilancia y administrativos sin los cuales no se lograría el funcionamiento que se requiere.

El problema con el SARS-CoV-2 es que este virus ha mostrado una alta contagiosidad (R.2-4), por lo que todo el personal ha tenido que modificar sustancialmente su forma de actuar dentro del hospital. Estos cambios son más notorios en el personal relacionado con la atención directa de los pacientes.

Por ello, sólo pacientes afectados y personal de salud que labora en el INER pueden acceder a las áreas clínicas. Todos usan traje de quirófano y se dejó de utilizar accesorios de vestimenta, como corbatas, mascadas, collares, etc., ya que constituyen potenciales asientos donde gotas que contienen el virus pueden alojarse y ser transmitidos. Los hombres que usaban barba o bigote se lo rasuraron y las mujeres utilizan el pelo recogido.

Se extreman los procesos de limpieza de áreas comunes y de áreas clínicas; eso incluye limpieza profesional con procesos de sanitización, limpieza convencional con cloro y limpieza personal de nuestras áreas de directas de trabajo (incluyendo equipo e instrumentos de trabajo). Las principales sustancias de limpieza incluyen solución de alcohol al $61-70 \%$, y la solución de hipoclorito de sodio al $1-5 \%$. El personal directamente en contacto con pacientes con COVID-19 ha recibido capacitación en cuanto al uso de equipo del protección personal (EPP) de acuerdo con los lineamientos de la Organización Mundial de la Salud., 4,5

El trabajo clínico evita exploraciones físicas innecesarias y el pase de visita se efectúa sólo con el personal indispensable. El objetivo es protegerse contra el contacto con aerosoles producidos por personas contagiadas (al hablar, estornudar o toser) y que pueden permanecer varias horas en diversas superficies donde se depositan, así como durante la realización de procedimientos clínicos generadores de aerosoles, entre los que resultan relevantes la intubación endotraqueal, la ventilación mecánica, la aspiración de la vía aérea, los pacientes con traqueostomía, los procedimientos de fisioterapia de tórax y la realización de broncoscopia. ${ }^{6}$ Éstos requieren protocolos estrictos y labor en equipo.

El EPP resulta un insumo de tal magnitud de importancia que debe ser considerado como prioritario, incluso por encima de la necesidad de ventiladores mecánicos.

\section{IMPACTO}

La presencia de una pandemia como la de COVID-19 implica la generación de una presión importante en el sistema de atención de la salud de cualquier país. La respuesta a esa situación de emergencia incluye el con- trol estricto de los recursos disponibles para enfrentar el problema.

Una labor esencial es lograr hacer que la sociedad entienda que su rol es importantísimo en el control de la pandemia: la contención y la mitigación pueden ayudar a reducir la afluencia de pacientes a los hospitales y que éstos no se vean abrumados e incapaces de brindar la atención médica. Los valores protagónicos en estos momentos son la solidaridad y la empatía; sin ellos es difícil hacer entender a la gente afectada que el beneficio de la atención médica deberá responder a la necesidad imperante en cada individuo. En una pandemia es muy probable que el sistema médico llegue a presentar saturación de instalaciones y deficiencia en ciertos insumos, obligando a los profesionales a asignar los recursos de manera juiciosa y bajo criterios especiales de selección, tal y como se realiza en desastres masivos, tanto naturales como no naturales. ${ }^{7}$ Asimismo, implica la optimización en el uso de áreas físicas hospitalarias, del equipamiento con el que se cuenta, pero sobre todo del esfuerzo importante que realiza todo el personal del equipo de atención de la salud: enfermeras, químicos, trabajadores sociales, ingenieros biomédicos, psicólogas, técnicos, camilleros, intendentes, administrativos, vigilantes, médicas y médicos, quienes hacemos un esfuerzo importante para mantener una atención de calidad.

Será primordial contar con la comunidad de familiares y allegados de los pacientes internados para comprender la total inconveniencia sanitaria que impide permitir visitar a sus seres queridos. Exige también del equipo de atención médica un esfuerzo por evitar posibles conflictos, mediante una conversación calmada, asertiva, abierta, transparente y basada en datos objetivos que busquen mantener la confianza. Se implementarán alternativas de comunicación donde los medios electrónicos deberán ser utilizados con eficiencia y en concordancia, acordes con los lineamientos de protección de privacidad (correo electrónico, videollamada, etcétera).

Pero, por encima de todo esto, el manejo terapéutico resulta ser limitado en cuanto a un tratamiento curativo como tal. Por ahora, todo parece limitarse al control de daños y al apoyo vital (como la ventilación mecánica). Los distintos tratamientos deben probarse en el campo de acción, aunque dentro de una estructura metodológica conocida: los ensayos clínicos controlados deberán producir los datos que guíen el mejor camino a seguir, por lo que la investigación clínica adquiere un valor ético primordial.

\section{COROLARIO}

La comunidad respiratoria mundial y de cada país enfrenta una responsabilidad muy grande, la cual está preparada para hacerlo. En México, el gremio neumológico está acostumbrado a los embates de la influenza, sin embargo, esta pandemia 
por SARS-CoV-2 es una situación totalmente nueva que está obligando a modificar la forma en que vemos la atención de la salud. Tenemos, por lo pronto, que adaptarnos, responder de acuerdo con cómo se vaya modificando la situación y fortalecernos con conocimiento de causa. Esto se llama resiliencia, otro valor que adquiere prioridad.

Pareciera que el mítico frasco de Pandora ha sido abierto nuevamente y que ésta ha dejado salir un infortunio más que habrá que controlar. Y ya se empezó a hacer. Está cambiando nuestra forma de vivir y de ejercer la profesión.

El esfuerzo requerirá de apoyos extraordinarios. Los «Hospitales COVID», como el INER, se están convirtiendo en una gran unidad de cuidados críticos. El sistema de salud nacional se está tensando; se requerirán recursos materiales, medicamentos, equipamiento y, sobre todo, personal capacitado para enfrentar el problema. Los costos de esto serán enormes, pero los costos de no hacerlo serían aún mayores.

El azote pestilente de la Yersinia pestis medieval forma parte de los infortunios también liberados por Pandora, y dio motivo para que Albert Camus escribiera La peste, donde nos advierte, tanto ahora como entonces, que «... esta crónica no puede ser el relato de la victoria definitiva», y nos regala un recordatorio no tan antiguo sobre la manera en que la solidaridad, la empatía y la resiliencia son valores morales que debemos rescatar como sociedad para abundar en los principios éticos de beneficencia y justicia en esta batalla microscópica que vamos, apenas, iniciando.

\section{REFERENCIAS}

1. Huang $\mathrm{C}$, Wang $\mathrm{Y}, \mathrm{Li} X, \mathrm{Ren} \mathrm{L}, \mathrm{ZhaO} \mathrm{J}, \mathrm{Hu} \mathrm{Y}$, et al. Clinical features of patients infected with 2019 novel coronavirus in Wuhan, China. Lancet 2020;395(10223):497-506. doi: 10.1016/S0140-6736(20)30183-5.

2. Secretaría de Gobernación. ACUERDO por el que se declara como emergencia sanitaria por causa de fuerza mayor, a la epidemia de enfermedad generada por el virus SARS-CoV2 (COVID-19). Diario Oficial de la Federación. 30 de marzo de 2020. Disponible en: http:// http://dof.gob.mx/2020/csg/csg_300320_ves.pdf

3. Secretaría de Salud [sitio web]. Reconversión Hospitalaria. Revisado el 5 de abril de 2020. Disponible en: https://coronavirus.gob.mx/wpcontent/uploads/2020/04/Documentos-Lineamientos-ReconversionHospitalaria.pdf

4. WHO. Hospital infection control guidance for Severe Acute Respiratory Syndrome (SARS). 2005. Disponible en: https://www. who.int/ihr/lyon/surveillance/infectioncontrol/en/

5. WHO. Infection prevention and control during health care when novel coronavirus (nCoV) infection is suspected. 2020a. Disponible en: https://www.who.int/publications-detail/infection-prevention-andcontrol-during-health-care-whennovel-coronavirus-(ncov)-infectionis-suspected

6. Tran K, Cimon K, Severn M, Pessoa-Silva CL, Conly J. Aerosol generating procedures and risk of transmission of acute respiratory infections to healthcare workers: a systematic review. PLoS One 2012;7(4):e35797. doi: 10.1371/journal.pone.0035797.

7. Christian MD, Sprung CL, King MA, et al. Task Force for Mass Critical Care; Task Force for Mass Critical Care. Triage: care of the critically ill and during pandemics and disasters: CHEST consensus statement. Chest 2014;146(4 Suppl):e61S-e74S. doi: 10.1378/chest.14-0736. 